\title{
Novel mutations in the TBX5 gene in patients with Holt-Oram Syndrome
}

\author{
Marianna P.R. Porto ${ }^{1}$, Naja Vergani ${ }^{1}$, Antonio Carlos C. Carvalho ${ }^{2}$, Mirlene C.S.P. Cernach ${ }^{1}$, \\ Decio Brunoni ${ }^{1}$ and Ana Beatriz A. Perez ${ }^{1}$ \\ ${ }^{1}$ Department of Morfologia, Universidade Federal de São Paulo, São Paulo, SP, Brazil. \\ ${ }^{2}$ Departamento de Medicina, Universidade Federal de São Paulo, São Paulo, SP, Brazil.
}

\begin{abstract}
The Holt-Oram syndrome (HOS) is an autosomal dominant condition characterized by upper limb and cardiac malformations. Mutations in the TBX5 gene cause HOS and have also been associated with isolated heart and arm defects. Interactions between the TBX5, GATA4 and NKX2.5 proteins have been reported in humans. We screened the TBX5, GATA4, and NKX2.5 genes for mutations, by direct sequencing, in 32 unrelated patients presenting classical (8) or atypical HOS (1), isolated congenital heart defects (16) or isolated upper-limb malformations (7). Pathogenic mutations in the TBX5 gene were found in four HOS patients, including two new mutations (c.374delG; c.678G > T) in typical patients, and the hotspot mutation c. $835 \mathrm{C}>\mathrm{T}$ in two patients, one of them with an atypical HOS phenotype involving lower-limb malformations. Two new mutations in the GATA4 gene were found in association with isolated upper-limb malformations, but their clinical significance remains to be established. A previously described possibly pathogenic mutation in the NKX2.5 gene $(c .73 \mathrm{C}>7)$ was detected in a patient with isolated heart malformations and also in his clinically normal father.
\end{abstract}

Key words: Holt-Oram syndrome, congenital heart disease, TBX5 gene, GATA gene, NKX2.5 gene, mutation analysis.

Received: July 3, 2009; Accepted: December 1, 2009.

The Holt-Oram syndrome (HOS) (MIM \#142900) is an autosomal dominant condition that has an estimated frequency of 1:100,000 live births (Basson et al., 1997) and comprises malformation of the upper limbs (involving mainly the pre-axial ray) and congenital heart defects (CHD). Atypical phenotypes have also been described (Brassington et al., 2003; Lehner et al., 2003; McDermott et al., 2005; Garavelli et al., 2008) and may present as isolated skeletal anomalies or cardiac defects (Lehner et al., 2003) or may include renal, craniofacial, axillary, tracheal and vertebral anomalies, deafness, abdominal situs inversus (Brassington et al., 2003; McDermott et al., 2005), and lower-limb malformations (Garavelli et al., 2008). Due to the high variability of the phenotype, evaluation of the apparently asymptomatic relatives is highly recommended and should include anamnesis, upper-limb radiographs, and cardiac evaluation by electrocardiogram (ECG) and echocardiogram (ECO).

HOS is caused by mutations in the TBX5 gene ( $\mathrm{Li}$ et al., 1997; Basson et al., 1999). The TBX5 gene (MIM *601620) maps to cytoband 12q24.1, belongs to the T-box family of transcription factors (Basson et al., 1997; Li et al., 1997 ) and is mainly expressed in the embryonic heart and upper-limb tissues (Bruneau et al., 2001). Although the

Send correspondence to Ana Beatriz A. Perez. Centro de Genética Médica, Rua Coronel Lisboa 966, 04020-041 São Paulo, SP, Brazil.E-mail: bialvarez@uol.com.br.
TBX5 gene is responsible for most cases of HOS, the genetic heterogeneity of the syndrome can lead to false diagnosis, causing the mutation rate in sporadic and atypical cases to be underestimated (Mori and Bruneau, 2004).

The GATA4 gene (MIM *600576) is a member of the GATA family of transcription factors, with expression mainly restricted to the heart and gonad tissues (Charron and Nemer, 1999). Protein GATA4 is one of the first transcripts to be found in the developing heart, where it precedes the expression of earliest cardiac differentiation markers (Charron and Nemer, 1999; Gilbert, 2006). Mutations in the GATA4 gene have been found in patients with congenital heart defects (Garg et al., 2003; Okubo et al., 2004; Hirayama-Yamada et al., 2005; Sarkozy et al., 2005), but no mutations have been related to upper-limb malformations so far.

The NKX2.5 (MIM *600584) protein plays an important hole in the genesis of the heart. Mutations in the NKX2.5 gene may lead to several types of cardiac malformations (Elliott et al., 2003). Previous studies have shown that the GATA4 protein interacts with both the NKX2.5 (Durocher et al., 1997) and the TBX5 (Garg et al., 2003) protein, and that these interactions can lead to upregulation of cardiogenesis in cells under differentiation.

Because of the wide phenotypic variability found in the HOS patients, we screened for mutations in the $T B X 5$, GATA4 and NKX2.5 genes in patients presenting with clas- 
sical HOS, classical HOS with feet anomalies, patients with isolated upper-limb malformations, and patients with isolated heart defects. We selected 32 unrelated patients and classified them into four categories: typical $\operatorname{HOS}(\mathrm{n}=8)$, atypical $\operatorname{HOS}(\mathrm{n}=1)$, isolated hand anomalies $(\mathrm{n}=7)$, and isolated heart defects $(n=16)$. Differential diagnosis for known conditions such as VACTERL sequence and Waardenburg syndrome was previously performed for exclusion from the sample. Informed consent in accordance with the guidelines established by the local institutional ethics boards was obtained.

Genomic DNA was isolated from all patients, their parents, and 50 healthy individuals, according to standard methods (Miller et al., 1988). Primers used to analyze the TBX5, GATA4, and NKX2.5 genes and the conditions for the polymerase chain reactions (PCR) were the same as previously described by other authors (Basson et al., 1997; Garg et al., 2003; Basson et al., 1999, respectively). PCR products were submitted to direct sequencing, using an $\mathrm{ABI}$ Prism 3100 automatic sequencer according to manufacturer's protocol. The obtained sequences were compared with the wild-type TBX5 (RefSeq NM_000192.3), GATA4 (RefSeq NM_002052.3), or NKX2.5 (RefSeq NM_004387.2) genomic sequences. The patients' clinical findings and detected mutations are listed in Table 1.

Four out of eight patients with typical HOS had mutations in the TBX5 gene. Patient HH17, a woman with ASD and triphalangeal thumbs (Figure 1A), had a previously described pathogenic mutation (c.835C > T/ p.R279X) that does not affect the TBX5-binding domain, but causes the loss of its C-terminal portion (Li et al., 1997), and is considered a hotspot mutation (Heinritz et al., 2005b). The patient also carried a TBX5 c.309C $>$ T mutation, in heterozygosis. This is a polymorphic silent mutation according to the "The
Human TBX5 Gene Mutation Database" (Heinritz et al., 2005a). The patient's son presented the same genotype, but a milder phenotype: shortened arms and no CHD.

Patient HH20 had a de novo novel mutation (c.374delG) in the TBX5 gene that resulted in a premature stop codon. This mutation eliminated the binding domain of the TBX5 protein, giving rise to a truncated protein with only 148 amino acids. This patient had a very severe phenotype, with bilateral upper-limb malformations (bilateral humerus hypoplasia, bilateral absence of the radius, three metacarpal bones, and two phalangeal fingers on the right side; and three metacarpal bones, and three phalangeal fingers (two of them syndactylic) on the left side, besides a severe heart malformation characterized by ASD, a ventricular septal defect and pulmonary hypertension (Figure 1B). Another previously described mutation, which resulted in a premature stop codon at the same position, was associated with the occurrence of a severe upper-limb malformation, but no heart defects were mentioned for that patient (Yang et al., 2000).

A novel mutation, c. $678 \mathrm{G}>\mathrm{T} / \mathrm{p} . \mathrm{K} 226 \mathrm{~N}$, located within the T-box domain of the TBX5 gene, was found in patient $\mathrm{HH} 24$ and her father. Both of them presented with severe congenital heart disease (OS-ASD, atrioventricular septal defect, pulmonary stenosis, hypertension, and mitral insufficiency), besides upper-limb and other malformations (triphalangeal thumbs, 11 pairs of ribs, and shortened scapular bone; Figure 1C). This mutation was predicted to impair the function of the TBX5 protein (PSIC score difference 1.966; PolyPhen), leading to hydrophobicity and charge changes at buried site. It was not found in the 100 control chromosomes tested.

Patient $\mathrm{HH} 25$ had a c. $804 \mathrm{C}>\mathrm{G}$ mutation in the TBX5 gene, a silent mutation that is not expected to be the cause

Table 1 - Clinical findings in patients with mutations

\begin{tabular}{|c|c|c|c|c|c|c|c|c|}
\hline \multirow[t]{2}{*}{ Patient } & \multirow[t]{2}{*}{ Gender } & \multicolumn{4}{|c|}{ Phenotype } & \multicolumn{3}{|r|}{ Mutation } \\
\hline & & Typical HOS & Atypical HOS & Only hand defects & Only heart defects & Gene & Exon & Genotype \\
\hline \multirow[t]{2}{*}{ HH17 } & $\mathrm{F}$ & Fam & - & - & - & $T B X 5$ & 4 & c.309C > T (SNP) \\
\hline & & & & & & & 8 & c. $835 \mathrm{C}>\mathrm{T}(\mathrm{p} . \mathrm{R} 279 \mathrm{X})$ \\
\hline $\mathrm{HH} 20$ & $\mathrm{~F}$ & $\mathrm{Sp}$ & - & - & - & $T B X 5$ & 5 & c.374delG (p.G125fsX149) \\
\hline $\mathrm{HH} 24$ & $\mathrm{~F}$ & Fam & - & - & - & $T B X 5$ & 7 & c.678G > T (p.K226N) \\
\hline $\mathrm{HH} 25$ & $\mathrm{~F}$ & $\mathrm{Sp}$ & - & - & - & $T B X 5$ & 8 & c.804C > G (SNP) \\
\hline HH8 & M & - & $\mathrm{Sp}^{*}$ & - & - & $T B X 5$ & 8 & c. $835 \mathrm{C}>\mathrm{T}(\mathrm{p} . \mathrm{R} 279 \mathrm{X})$ \\
\hline \multirow[t]{2}{*}{$\mathrm{HH} 2$} & $\mathrm{~F}$ & - & - & $\mathrm{Sp}$ & - & $T B X 5$ & 4 & c. $309 \mathrm{C}>\mathrm{T}(\mathrm{SNP})^{* *}$ \\
\hline & & & & & & GATA4 & 4 & c. $[997+23 \mathrm{~A}>\mathrm{T} ; 997+56 \mathrm{C}>\mathrm{A}]$ \\
\hline HH4 & M & - & - & $\mathrm{Sp}$ & - & GATA4 & 1 & c.392C > G (p.A131G) \\
\hline \multirow[t]{2}{*}{ CHD1 } & M & - & - & - & $\mathrm{Sp}$ & $N K X 2.5$ & 1 & c. $73 \mathrm{C}>\mathrm{T}(\mathrm{p} . \mathrm{R} 25 \mathrm{C})$ \\
\hline & & & & & & GATA4 & 1 & c543C > T (SNP) \\
\hline CHD5 & $\mathrm{F}$ & - & - & - & Fam & $T B X 5$ & 4 & c. $309 \mathrm{C}>\mathrm{T}(\mathrm{SNP})$ \\
\hline
\end{tabular}

HOS: Holt-Oram syndrome. HH: heart-hand syndrome. CHD: congenital heart defect. Sp: sporadic cases. Fam: familial cases.

Bold: novel mutations and polymorphisms. *Feet anomaly. **Mutation found in homozygosis. 
A.

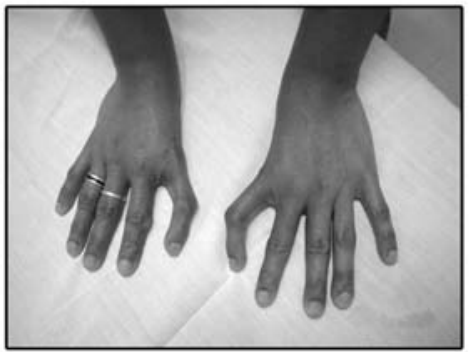

B.

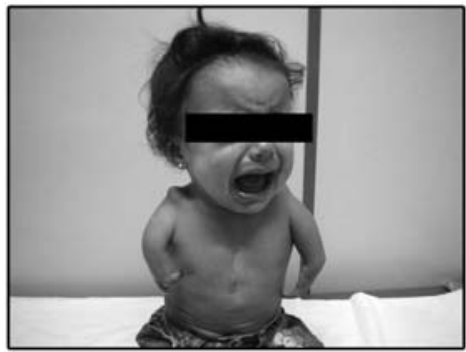

C.

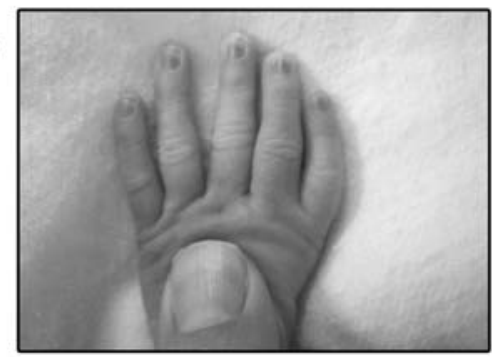

D.

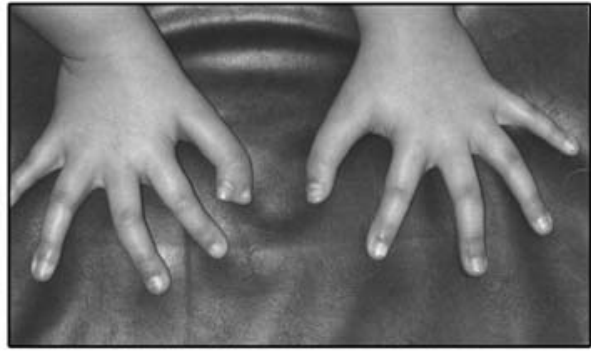

F.
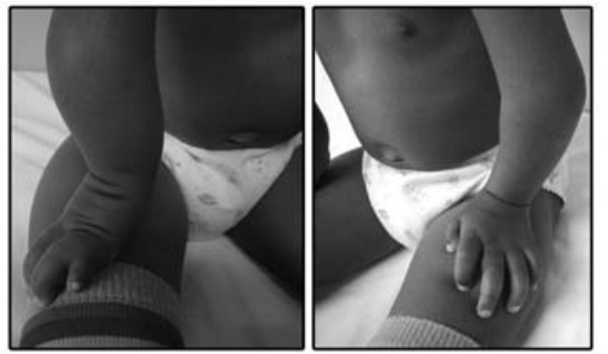

E.

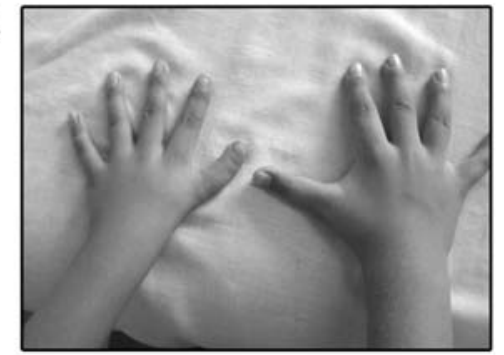

G.

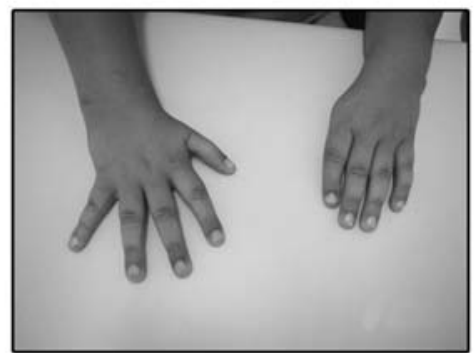

Figure 1 - Upper-limb malformations found in patients. (A) HH17: triphalangeal thumbs. (B) HH20: at right, bilateral humerus hypoplasia and absence of radius, three metacarpal bones, and two phalangeal fingers; at left, three metacarpal bones, and three phalangeal fingers, two of them syndactylic. (C) HH24: triphalangeal thumbs. (D) HH25: preaxial polydactilia of the right thumb with duplication of the distal phalanx (presence of nails was observed on both the duplicated phalanges), distal implantation of the left thumb. (E) HH8: brachymesophalangism of the fifth finger and high implantation of the left thumb. (F) HH2: At left, radioulnar synostosis, and hypoplasia of the distal and middle phalanges of the first and fifth digits; at right, synostosis of ulna and humerus, hypoplastic radius, two digital rays of hand. (G) HH4: At right, hypoplastic thumb (low articulated) and short phalanges; at left, radial deviation, and absence of the thumb.

of the typical HOS clinical features (ASD, VSD, mitral valve insufficiency, dilatation of the left atrium and the pulmonary artery, preaxial polydactyly of the right thumb with duplication of the distal phalanx (presence of nails was observed on both the duplicated phalanges), distal implantation of the left thumb, mild hemithorax hypoplasia, upper-limb supination limited to the right side, and a sacralized transition vertebra; Figure 1D). The mutation was not found in the 100 control chromosomes tested.

The atypical HOS patient $\mathrm{HH} 8$ had a de novo c. $835 \mathrm{C}$ $>$ T mutation, the same as found in Patient HH17. The clinical findings were ostium secundum atrial septal defect (OS-ASD) and upper-limb malformation (brachymesophalangism of the fifth finger and high implantation of the left thumb; Figure 1E), all of which are common findings in HOS (Li et al., 1997). This patient also presented lower-limb malformation (agenesis of the distal phalanx of the fifth toe), which is an unusual finding among
HOS patients. A recent study (Garavelli et al., 2008) describes a family with three affected individuals, one of which presents a foot anomaly. The authors included this patient in the group of atypical Holt-Oram syndrome phenotypes. Faria et al. (2008) reported a TBX5 missense mutation (V263M) in a Brazilian family with atrial septal defect and postaxial hexadactyly of both feet.

In four of our typical HOS patients, no mutations were detected. In addition to the possibility of the involvement of other genes, large deletions in the investigated genes might have gone undetected by direct sequencing (Borozdin et al., 2006).

Two out of the 16 patients with isolated heart anomalies had mutations in TBX5, GATA4, and NKX2.5. Patient CHD5 carried the c.309C $>$ T polymorphism in the TBX5 gene. Her parents did not have this polymorphism. She had an isolated heart defect of the OS-ASD type, and her three brothers presented valve defects, but they were not avail- 
able for mutation analysis. Patient CHD1 presented a presumptively pathogenic mutation in the $N K X 2.5$ gene (c.73C > T/p.R25C), together with the c.543C > T polymorphism in the GATA4 gene. This patient had OS-ASD, but his father who carried the same mutations showed no heart malformation. The $N K X 2.5$ p.R25C mutation was previously described in patients with a wide spectrum of congenital heart diseases, from conduction defects to Tetralogy of Fallot (Benson et al., 1999; McElhinney et al., 2003). However, the frequency of this mutation in black control subjects was $4.7 \%$ (Goldmuntz et al., 2001), which is suggestive of low penetrance or no involvement in CHD.

Two out of the seven patients with isolated upper-limb anomalies had mutations in TBX5 and/or GATA4. Patient $\mathrm{HH} 2$ had radioulnar synostosis of the left arm and hypoplasia of the distal and middle phalanges of the first and fifth digits (Figure 1F). At right, she had synostosis of ulna and humerus, a hypoplastic radius, and only two digital rays of the right hand (the first-finger phalanges were hypoplastic, and only two metacarpal bones were observed), as shown in Figure F. No congenital heart disease was diagnosed in the patient or in her family (ECO and ECG were normal). Mutational analysis of the GATA4 gene showed two novel de novo intron mutations, c. [997+23A > $\mathrm{T} ; 997+56 \mathrm{C}>\mathrm{A}]$, in the same allele. These mutations were located far from the splicing sites, and the potential instability of the mRNA remains to be accessed. They were not found in the 100 control chromosomes tested. The patient also presented the TBX5 c.309C $>\mathrm{T}$ polymorphism in homozygosis.

Patient HH4 had a hypoplastic thumb with low implantation and shortened phalanges of the right hand. The left hand showed radial deviation and absence of the thumb (Figure 1G). No congenital heart disease was observed in him or his parents (ECO and ECG were normal). The GATA4 gene showed a novel nonsense mutation, c.392C > $\mathrm{G}$ (p.A113G), located in the transcriptional activation domain 1. This variant was predicted to be benign (PSIC score difference 1.191), according to the PolyPhen program (Ramensky et al., 2002). It was not found in the patient's parents or in the 100 control chromosomes.

So far, GATA4 mutations have not been described in association with isolated upper-limb defects, but this is a possibility that deserves further investigation.

\section{Acknowledgments}

The authors thank Dr. Janete M Cerutti and Rosana Tamanaha for their help with the sequencing analysis, and Dr. Márcia Gonçalves Ribeiro (UFRJ), Dr. Denise Pontes Cavalcanti (UNICAMP), Dr. Eliana M. Kahatsu (Leonor Mendes de Barros Hospital), and the Orthopedics Clinic of UNIFESP for referring patients. This work was financially supported by FAPESP (Fundação de Amparo à Pesquisa do Estado de São Paulo; grant 03/01623-0.

\section{References}

Basson CT, Bachinsky DR, Lin RC, Levi T, Elkins JA, Soults J, Grayzel D, Kroumpouzou E, Traill TA, Leblanc-Straceski J, et al. (1997) Mutations in human TBX5 cause limb and cardiac malformation in Holt-Oram syndrome. Nat Genet 15:30-35.

Basson CT, Huang T, Lin RC, Bachinsky DR, Weremowicz S, Vaglio A, Bruzzone R, Quadrelli R, Lerone M, Romeo G, et al. (1999) Different TBX5 interactions in heart and limb defined by Holt-Oram syndrome mutations. Proc Natl Acad Sci USA 96:2919-2924.

Benson DW, Silberbach GM, Kavanaugh-McHugh A, Cottrill C, Zhang Y, Riggs S, Smalls O, Johnson MC, Watson MS, Seidman JG, et al. (1999) Mutations in the cardiac transcription factor $N K X 2.5$ affect diverse cardiac development pathways. J Clin Invest 104:1567-1573.

Borozdin W, Acosta AMBF, Bamshad MJ, Botzenhart EM, Froster UG, Lemke J, Schinzel A, Spranger S, McGaugran J, Wand D, et al. (2006) Expanding the spectrum of TBX5 mutations in Holt-Oram syndrome: Detection of two intragenic deletions by quantitative real time PCR, and report of eight novel point mutations. Hum Mutat 27:975-976.

Brassington A-ME, Sung SS, Toydemir RM, Le T, Roeder AD, Rutherford AE, Whitby FG, Jorde LB and Bamshad MJ (2003) Expressivity of Holt-Oram syndrome is not predicted by $T B X 5$ genotype. Am J Hum Genet 73:74-85.

Bruneau BG, Nemer G and Schmitt JP (2001) A murine model of Holt-Oram syndrome defines roles of the T-box transcription factor Tbx5 in cardiogenesis and disease. Cell 106:709-721.

Charron F and Nemer M (1999) GATA transcription factors and cardiac development. Sem Cell Dev Biol 10:85-91.

Durocher D, Charron F, Warren R, Schwartz RJ and Nemer M (1997) The cardiac transcription factors $\mathrm{Nkx} 2-5$ and GATA4 are mutual cofactors. EMBO J 16:5687-5696.

Elliott DA, Kirk EP, Yeoh T, Chandar S, McKenzie F, Hayes P, Feneley M and Harvey RP (2003) Cardiac homeobox gene NKX2.5 mutations and congenital heart disease. J Am Coll Cardiol 41:2072-2076.

Faria MHG, Habenhorst SHB, Pereira AC and Krieger JE (2008) A novel TBX5 mutation (V263M) in a family with atrial septal defects and postaxial hexadactyly. Int $\mathrm{J}$ Cardiol 130:30-35.

Garavelli L, De Brasi D, Verri R, Guareschi E, Cariola F, Melis D, Calcagno G, Salvatore F, Unger S and Sebastio G (2008) Holt-Oram syndrome associated with anomalies of the feet. Am J Med Genet A 146:1185-1189.

Garg V, Kathiriya IS, Barnes R, Schluterman MK, King IN, Butler CA, Rothrock CR, Eapen RS, Hirayama-Yamada K, Joo $\mathrm{K}$, et al. (2003) GATA4 mutations cause human congenital heart defects and reveal an interaction with $T B X 5$. Nature 424:443-447.

Gilbert SF (2006) Developmental Biology. Sinauer, Sunderland, $785 \mathrm{pp}$.

Goldmuntz E, Geiger E and Benson DW (2001) NKX2.5 mutations in patients with Tetralogy of Fallot. Circulation 104:2565-2568.

Heinritz W, Shou L, Moschik A and Froster UG (2005a) The human TBX5 gene mutation database. Hum Mutat 26:397-398.

Heinritz W, Moschik A, Kujat A, Spranger S, Heilbronner H, Demuth S, Bier A, Tihanyi M, Mundlos S, 
Gruenauer-Kloevekorn C, et al. (2005b) Identification of new mutations in the TBX5 gene in patients with Holt-Oram syndrome. Heart 91:383-384.

Hirayama-Yamada K, Kamisago M, Akimoto K, Aotsuda H, Nakamura Y, Tomita H, Furutani M, Imamura S, Takao A, Nakasawa M, et al. (2005) Phenotypes with GATA4 or $N K X 2.5$ mutations in familial atrial septal defect. Am J Med Genet A 135:47-52.

Lehner R, Goharkhay N, Tringler B, Fasching C and Hengstschläger M (2003) Pedigree analysis and descriptive investigation of three classic phenotypes associated with Holt-Oram syndrome. J Reprod Med 48:153-159.

Li QY, Newbury-Ecob RA, Terrett JA, Wilson DI, Curtis ARJ, Yi CH, Gebuhr T, Bullen PJ, Robson SC, Strachan T, et al. (1997) Holt-Oram syndrome is caused by mutations in TBX5, a member of the Brachyury (T) gene family. Nat Genet 15:21-29.

McDermott DA, Bressan MC, He J, Lee JS, Aftimos S, Brueckner M, Gilbert F, Graham GE, Hannibal MC, Innis JW, et al. (2005) TBX5 genetic testing validates strict clinical criteria for Holt-Oram syndrome. Pediatr Res 58:981-986.

McElhinney DB, Geiger E, Blinder J, Benson W and Goldmuntz $\mathrm{E}(2003) N K X 2.5$ mutations in patients with congenital heart disease. J Am Coll Cardiol 42:1650-1655.

Miller AS, Dykes DD and Polesky HF (1988) A simple salting out procedure of extracting DNA from human nucleated cells. Nucleic Acids Res 16:1215.

Mori AD and Bruneau BG (2004) TBX5 mutations and congenital heart disease: Holt-Oram syndrome revealed. Curr Opin Cardiol 19:211-215.
Okubo A, Miyoshi O, Baba K, Takagi M, Tsukamoto K, Kinoshita A, Yoshiura K, Kishino K, Ohta T, Niikawa N, et al. (2004) A novel GATA4 mutation completely segregated with atrial septal defect in a large Japanese family. J Med Genet 41:e97.

Packham EA and Brook JD (2003) Interaction makes the heart grow stronger. Trends Mol Med 9:407-409.

Ramensky V, Bork P and Sunyaev S (2002) Human non-synonymous SNPs: Server and survey. Nucleic Acids Res 30:3894-3900.

Sarkozy A, Conti E, Neri C, D'Agostino R, Digilio MC, Esposito G, Toscano A, Marino B, Pizzuti A and Dallapiccola B (2005) Spectrum of atrial septal defects associated with mutations of NKX2.5 and GATA4 transcription factors. J Med Genet 42:e16.

Yang J, Hu D, Xia J, Yang Y, Ying B, Hu J and Zhou X (2000) Three novel TBX5 mutations in Chinese patients with Holt-Oram syndrome. Am J Med Genet 92:237-240.

\section{Internet Resources}

Online Mendelian Inheritance in Man (OMIM), http://www.ncbi.nlm.nih.gov/entrez/dispomim.cgi?id 142900 (June 26, 2009).

The Human TBX5 Gene Mutation Database, http://www.medizin.uni-leipzig.de/ genetik/TBX5 (June 26, 2009).

PolyPhen, http://coot.embl.de/PolyPhen/ (August 26, 2008).

Associate Editor: John M. Optiz

License information: This is an open-access article distributed under the terms of the Creative Commons Attribution License, which permits unrestricted use, distribution, and reproduction in any medium, provided the original work is properly cited. 